\title{
Article \\ Study on Operating Cost Economy of Battery-Swapping Heavy-Duty Truck in China
}

\author{
Xiaoyuan Wu *, Pengyu Liu and Xinbao Lu \\ School of Automotive Studies, Tongji University, 4800 Cao'an Road, Shanghai 201804, China; \\ liupengyu@tongji.edu.cn (P.L.); $1453425 @$ tongji.edu.cn (X.L.) \\ * Correspondence: xywu@tongji.edu.cn
}

check for updates

Citation: Wu, X.; Liu, P.; Lu, X. Study on Operating Cost Economy of Battery-Swapping Heavy-Duty Truck in China. World Electr. Veh. J. 2021, 12, 144. https://doi.org/10.3390/ wevj12030144

Academic Editors: C. C. Chan, Yoichi Hori, James L. Kirtley, Jr., Joeri Van Mierlo, Myoungho Sunwoo and Xuhui Wen

Received: 16 July 2021

Accepted: 1 September 2021

Published: 4 September 2021

Publisher's Note: MDPI stays neutral with regard to jurisdictional claims in published maps and institutional affiliations.

Copyright: (C) 2021 by the authors. Licensee MDPI, Basel, Switzerland. This article is an open access article distributed under the terms and conditions of the Creative Commons Attribution (CC BY) license (https:// creativecommons.org/licenses/by/ $4.0 /)$.

\begin{abstract}
In recent years, battery-swapping heavy-duty trucks have seen rapid growth in China. Summarizing from the practical experiences gained in this development, and starting from market research and analysis of the most typical city of application case, Beijing, we aim to achieve the following: (i) Establish an operating cost model for battery-swapping heavy-duty trucks throughout a full operation cycle from the perspective of a heavy-duty truck freight transport capacity operator, based on four key cost dimensions, including transportation equipment, operation and maintenance, environmental protection compensation, and battery recycling compensation. (ii) Calculate and compare the operating cost economy of battery-swapping heavy-duty trucks and other types of heavy-duty truck under different energy supplement modes, including charging, hydrogenation, and diesel. (iii) Propose suggestions for faster and more successful heavy-duty truck electrification. The results indicate that battery-swapping heavy-duty trucks have good cost economy in a full operation cycle under specific scenario, and their economy will be improved with the popularization of battery-swapping stations.
\end{abstract}

Keywords: new energy vehicle; heavy-duty truck (HDT); battery-swapping; operating cost; economy

\section{Introduction}

The terms "BS-HDT", "C-HDT", "FC-HDT", and "D-HDT" in this paper refer to a heavy-duty truck (HDT) that adopts the following four different energy supplement modes in sequence, namely, battery-swapping, power charging, hydrogenation, and diesel refueling. Classified by usage purposes, "BS-HDT", "C-HDT", "FC-HDT", and "D-HDT" each have three different vehicle types, including semi-trailer tractors, trucks, and special vehicles for garbage transportation or muck removal. The term "capacity operator" refers to an enterprise that provides both HDT vehicles and drivers and makes profits through its freight transport services [1].

In recent years, China's HDT electrification has been growing at an accelerated pace, which is driven by market demand, national strategies of carbon peaking in 2030, and carbon neutralization in 2060 (hereinafter referred to as "Double Carbon" goal), as well as local requirements on energy conservation and emission reduction. The three types of new energy vehicle of HDT, including BS-HDT, C-HDT, and FC-HDT, are all regarded as support objects to gradually replace the D-HDT for China's HDT electrification. Among the three types of new energy HDT, the two kinds of electric HDT (BS-HDT and C-HDT) are mainly promoted and applied, while the hydrogen powered HDT (FC-HDT) is still very rare due to the lack of both mature products and popularization of hydrogenation facilities. Taking 2020 as an example, 98.7\% of total sales of 2619 new energy HDTs in China were electric HDTs. Compared with the power-charging mode, the battery-swapping mode has been adopted gradually for electric HDT operation because of its outstanding advantages in reducing operating costs and improving operating efficiency, which are discovered by enterprises through their practice and exploration [2]. The operating economy of BS-HDT has been constantly verified by typical specific scenarios in Beijing and other cities' practice. 
Since the application practice of BS-HDT has just started in actual scenarios, in terms of the theoretical research on BS-HDT, there are rare comparative studies on the operating economy of BS-HDT and HDTs under different energy supplement modes from the perspective of freight transport capacity operators. By March 2021, most existing studies conducted on the operating economy of BS-HDT remained in the stage of business analysis. Due to the short time of large-scale operation of BS-HDTs and the lack of theoretical research, some researchers, like Yunfei, $\mathrm{W}$., only focused on analyzing the energy cost difference between BS-HDT and D-HDT in view of "fuel-electricity price difference" and drew a conclusion that each BS-HDT can save USD 10,870 per year compared with DHDT [3]. Yixin, C. and Hewu, W. compared and analyzed the business models of charging and battery-swapping taxis in the initial operation in Hangzhou and Shenzhen, China [4], which provides a reference for economic analysis and model methods for our research on the cost economy of BS-HDT. There is also a lack of consideration of cost factors affecting the full operation cycle, such as environmental protection compensation costs and battery recycling compensation costs, as well as an absence of a basic analysis on the economic aspects after the popularization of battery-swapping stations.

Therefore, in order to study the operating economy of BS-HDT more pertinently, we comprehensively summarize the practice of China's HDT industry and operation in recent years and select the largest fleet of BS-HDTs operation under specific scenarios in Beijing (hereinafter referred to as "Beijing Case") as the typical case to analyze. Targeting the most widely used battery-swapping tractors, we establish a cost model in a full operation cycle from the perspective of a freight transport capacity operator. Based on calculating the operating cost of BS-HDT, we compare and analyze the operating economy of BS-HDT and that of C-HDT, FC-HDT, and D-HDT. Furthermore, proposals for the promotion of BS-HDT operation in more scenarios in the future and the faster development of HDT electrification in China and even the world are put forward.

\section{Methods}

In general, a literature review, a site survey, an expert interview, a case study, and a comparative study were the main methods we adopted in this paper. Through the literature review, we carried out a preliminary overview of the BS-HDT industry. By interviewing industry experts of BS-HDT operators, such as Enneagon Energy Technology Co., Ltd., Shanghai, China, etc., and using the on-site survey of cities where BS-HDTs have been applied, including Beijing, Nanjing, and Shanghai, we understand the basic composition of operation costs under the actual application scenario and obtain the key data of relevant cost items. In terms of the operating cost model constructed, we select the simple linear model of economics to establish a full cycle operating cost model of BS-HDT. After calculating the total operating costs of HDTs under the four different energy supplement modes, respectively, we compare the economics. Finally, the conclusion is drawn through discussion and analysis. We use international currency to express different costs instead of Chinese currency, and the exchange rate of USD 1.00 is CNY 6.90 (a yearly currency exchange rate in 2020).

\section{Results}

\subsection{BS-HDT Development Status in China \\ 3.1.1. HDT Electrification Status}

In the past five years, China's HDTs have been developing rapidly, with annual sales increasing from 728,000 units in 2016 to 1,623,000 units in 2020, while the number of HDT owners by 2020 reached 15,000,000. Although the number of HDT owners only accounts for $5 \%$ of China's total automobile ownership by 2020, which is approximately $280,000,000$, HDTs' fuel consumption is equivalent to 200,000,000 passenger vehicles', while HDTs' emissions exceed $50 \%$ of the total automobiles' emissions [5]. Because HDT application has become a key area of energy conservation and emission reduction in China since 2017, sales of electric HDTs show an explosive growth trend, as illustrated in Figure 1. Despite 
the severe impact of the epidemic, sales of electric HDTs still reached 2619 in 2020, which is 3.8 times that in 2017. By the end of 2020, electric HDT ownership in China reached 9500 units, but electrification rate of HDTs was still low at only $0.16 \%$. There is still a large market space for electric HDTs in the future. Compared to the C-HDT, which has the first application since 2017 and the largest total scale of the electric HDTs by 2020 in China, the BS-HDT has become increasingly preferred in HDT electrification since 2019. The main and direct factors that accelerate the development of BS-HDT can be seen as strengthened support for battery-swapping mode from the country since the past year, the expanding market demand for BS-HDT, and the increasing number of HDT makers that have been actively developing and supplying higher quality BS-HDTs. In addition, the BS-HDT market in China has also been encouraged and demonstrated by the earlier-started and basically economical and efficient operation of battery-swapping taxies in more than 20 cities conducted by battery-swapping technology and service provider Aulton and battery-swapping passenger-vehicle makers, BAIC, SAIC, FAW, and Changan, since 2015. Only in the first half of 2021, the order volume of BS-HDT exceeded 10,000 units.

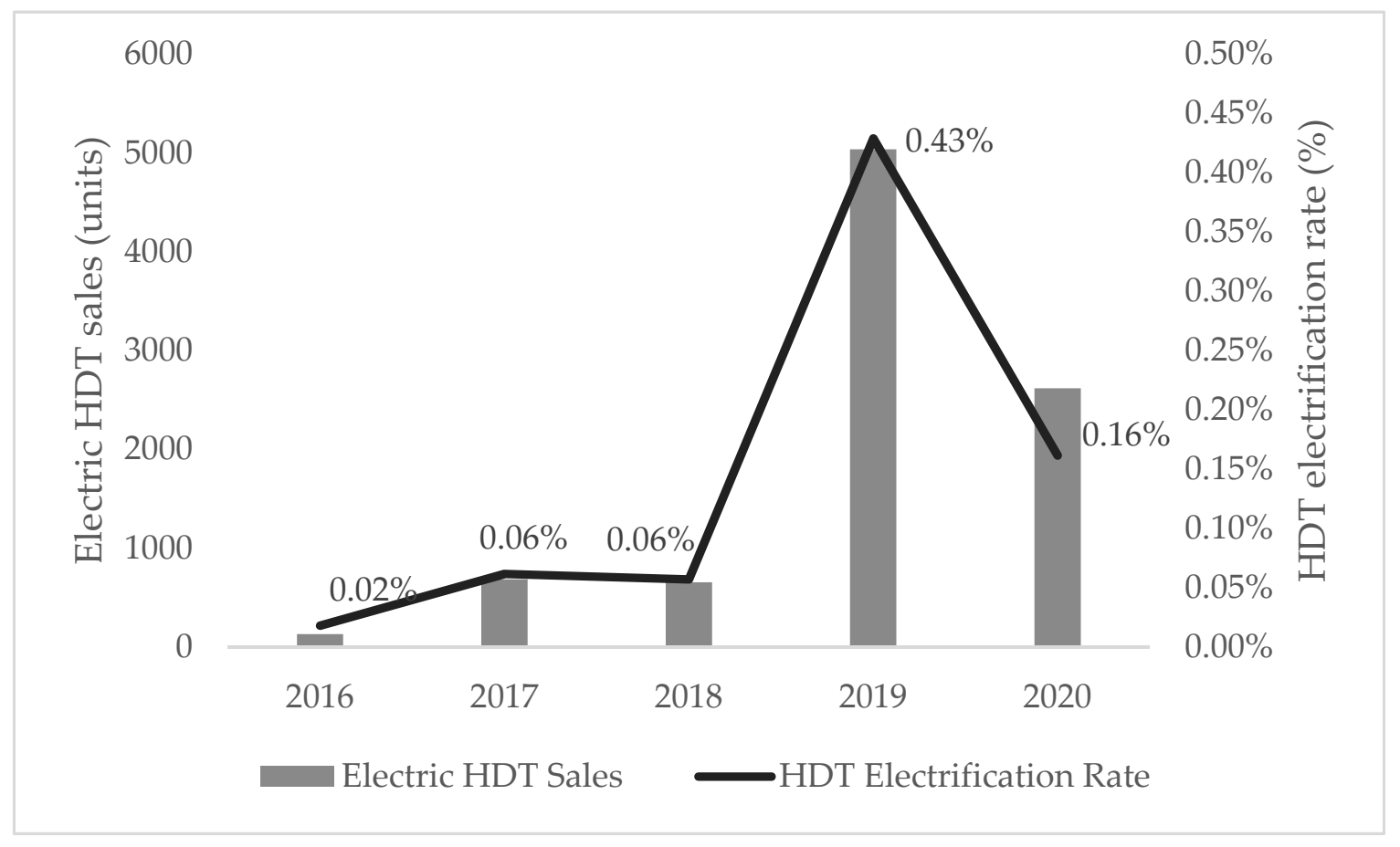

Figure 1. Electric HDT sales and HDT electrification rate in China, from 2016 to 2020.

\subsubsection{BS-HDT Application Practice}

Electric HDT, which is generally loaded with a large battery capacity (about $300 \mathrm{kWh}$ ), requires a long energy supplement time under charging mode. It takes $1.5 \mathrm{~h}$ on average for a full charging, even deploying high-power fast charging. Because an electric HDT's full charging time requires far more than a few minutes for a D-HDT to refuel, the electric HDT's operating time that can be used for business is significantly squeezed. Regarding the fact that the energy supplement time of a BS-HDT is usually about 5 minutes, which is close to that of D-HDT [6], freight capacity enterprises and their partners in Beijing have taken the lead in operating electric HDTs with battery-swapping mode over the past two years.

By the beginning of 2021, China's BS-HDTs have basically covered most application scenarios of traditional D-HDTs except for long-distance intercity freight of $200 \mathrm{~km}$ and above, mainly including short-transfer in specific parks, short-distance and heavy-haul 
freight, and municipal-dedicated freight. The main vehicle types and application scenario features of BS-HDTs are shown in Table 1.

Table 1. Main vehicle types and application scenarios of BS-HDT.

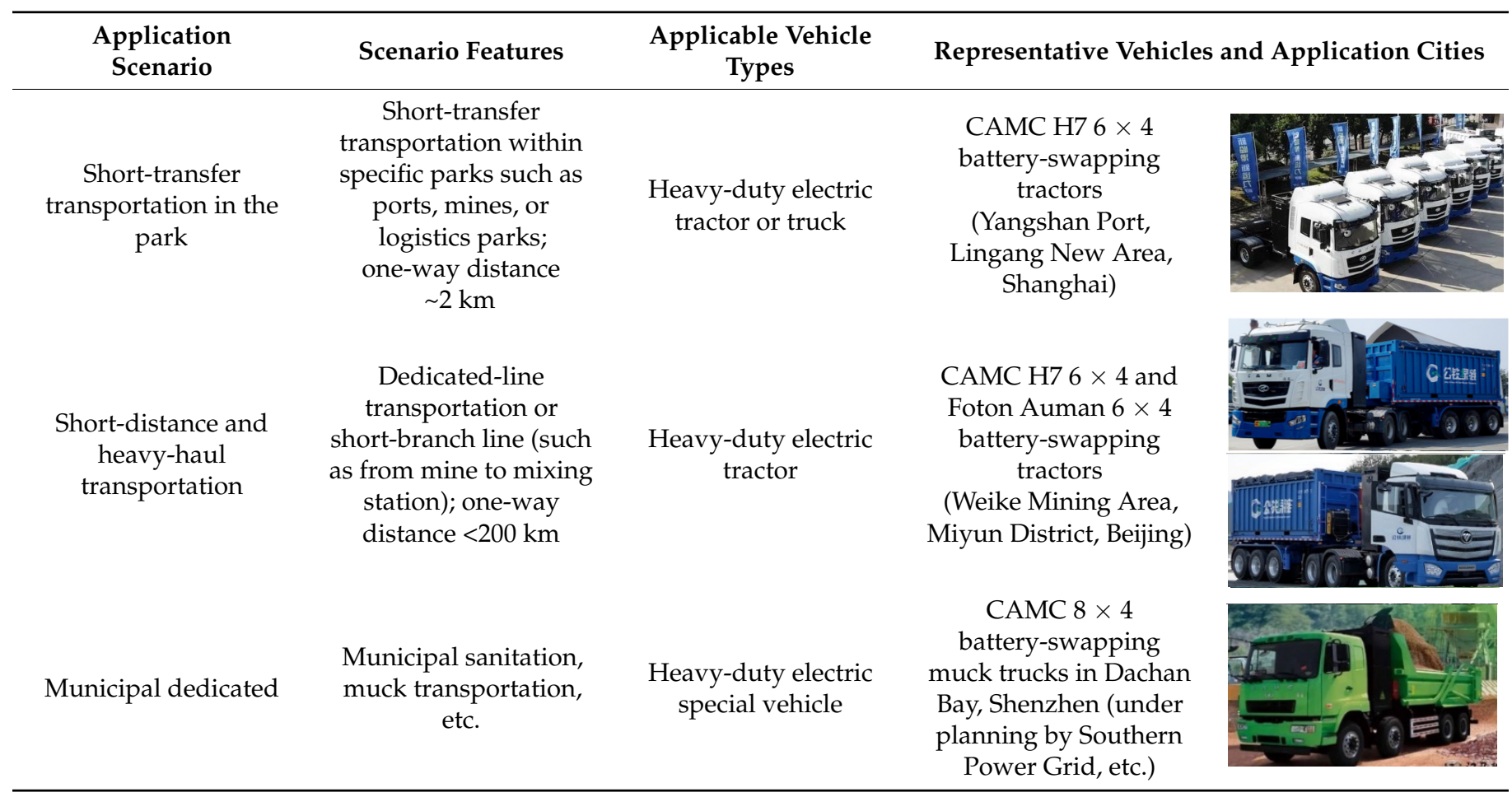

Among the three types of new energy HDTs for different usage purposes, the electric tractor is the first HDT type with the earliest and the largest application scale in adopting a battery-swapping mode. The most-used vehicle type is CAMC H7 among all the electric heavy-duty tractors operated under battery-swapping mode by early 2021. Only in Beijing, there have been nearly 100 units of CAMC H7 in operation. The "Beijing Case" is the most typical practice case in a single city and a single special scenario in which the earliest and largest BS-HDT fleet had been operated by early 2021 in China. Figure 2 shows the battery-swapping process of BS-HDT in the battery-swapping station of the "Beijing Case".

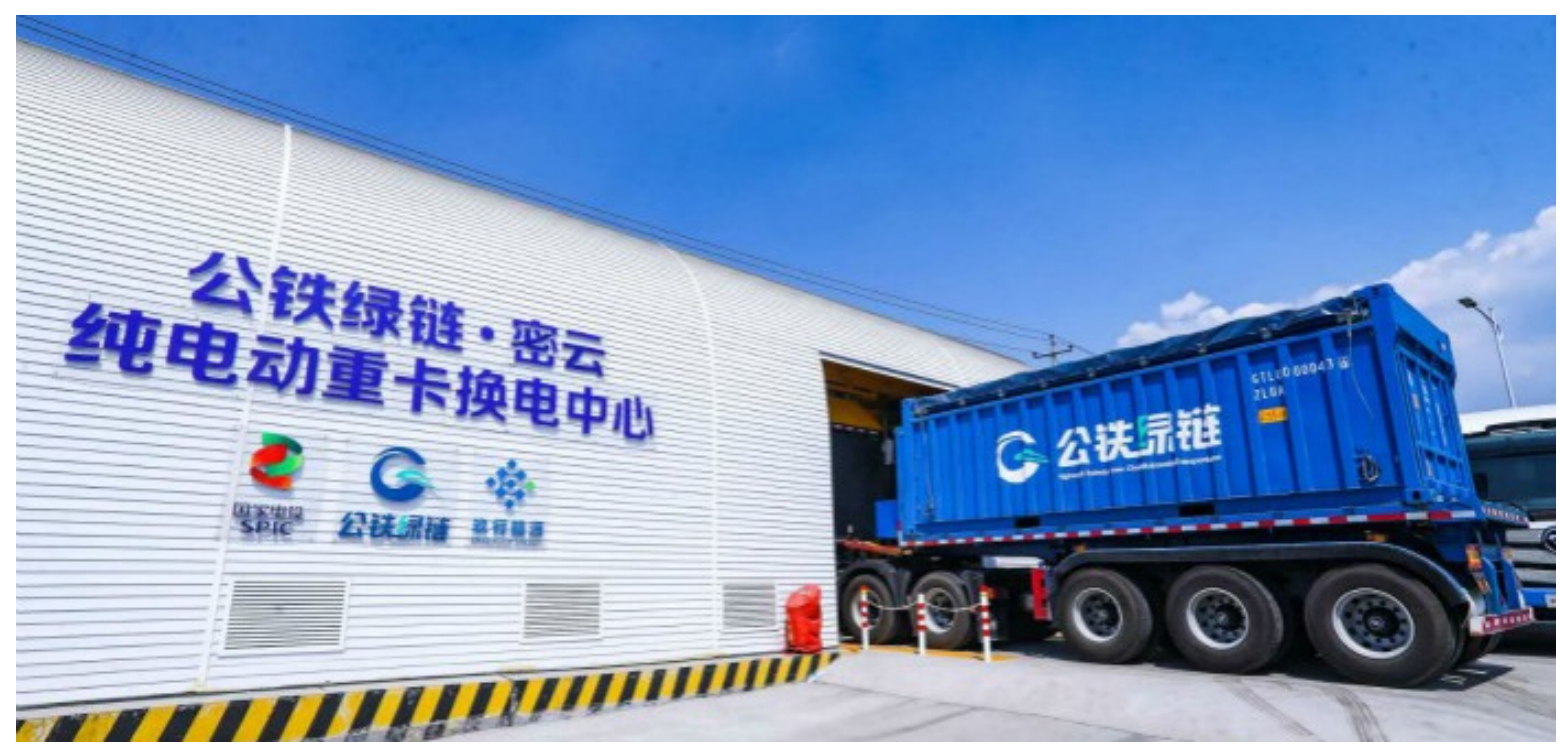

Figure 2. Battery-swapping station of BS-HDT and battery-swapping process in the "Beijing Case". 
In the "Beijing Case", Highway and Railway Green Chain Multimodal Transportation Co., Ltd., Beijing, China (hereinafter referred to as "High Railway Green Chain"), is the main operating enterprise of BS-HDTs. Other major enterprises include Enneagon Energy Technology Co., Ltd., Shanghai, China (hereinafter referred to as "Enneagon Energy"), that provides battery-swapping technology and service, and State Power Investment Corporation and Ronghe Financial Leasing Co., Ltd., Shanghai, China (hereinafter referred to as "SPIC and RHZL"), that provides capital and industrial resources. From the end of 2019 to the beginning of 2021, the tripartite cooperation has operated 106 electric heavyduty tractors, constructed and put three battery-swapping stations into use to full-range in the zero-emission transportation mode of BS-HDTs for short-distance transportation of sand, gravel, and building materials in Beijing. The typical BS-HDT operation cooperation mode of the freight transport capacity operator, the "High Railway Green Chain", and other major stakeholders in the "Beijing Case" are illustrated in Figure 3.

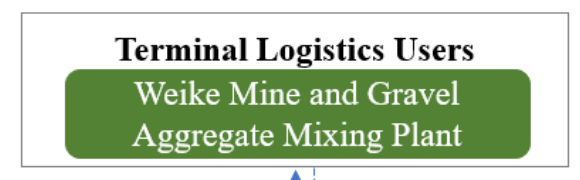

Freight capacity output ${ }_{\downarrow}$ Cash

Freight Capacity Operator

\section{Highway \& Railway Green Chain Multimodal Transportation}

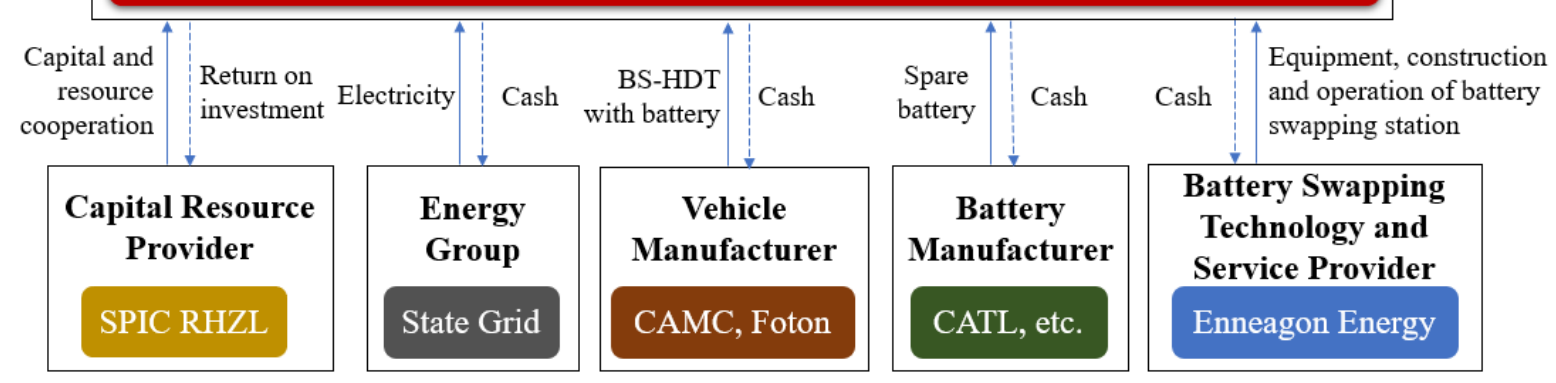

Figure 3. Schematic diagram of BS-HDT operation cooperation mode in the "Beijing Case".

Among the 106 BS-HDTs operated in the "Beijing Case", 96 are CAMC H7 batteryswapping tractors, each loaded with a battery capacity of $282 \mathrm{kWh}$. The tractor can get a maximum range of $170 \mathrm{~km}$ by swapping its battery once in 6 minutes. Because the round-trip distance of a single freight transportation is 120-160 km, two drivers can run four times in turn with one tractor and reach a total mileage of a maximum of 700 or $400 \mathrm{~km}$ on average per day. Compared with the 15 charging-mode HDTs of the same brand that have been used in the "Beijing Case" before, the battery-swapping mode greatly improves the utilization efficiency of electric HDTs. According to surveys, the cooperation partners led by the "High Railway Green Chain" will double the number of BS-HDTs in operation in 2021 and replicate the BS-HDTs operation mode in Xiong'an and other cities, thus vigorously promoting more BS-HDTs.

\subsection{Operating Economy of BS-HDT Based on "Beijing Case"}

Based on the practical "Beijing Case" of BS-HDTs, the operating cost model of BSHDT in a full operation cycle from the perspective of freight transport capacity operators is established.

\subsubsection{Operating Cost Model of BS-HDT in a Full Operation Cycle}

In general, the operating cost of traditional D-HDTs usually consists of vehicle purchase fees, diesel fees, insurance fees, toll charges, maintenance fees, and drivers' salaries [7]. 
Differing from the traditional D-HDTs' operating cost structure, costs of power batteries and battery-swapping stations need to be considered when analyzing BS-HDTs in the "Beijing Case". Because electric HDTs are environmentally friendly, the contribution of their emission reduction and remaining value of power batteries [8] is also included in the operating cost structure as compensation cost items. In addition, since BS-HDTs have been mainly used for demonstration operations in specific short-distance areas by the beginning of 2021, the toll charge for long-distance transportation of BS-HDTs can be temporarily ignored.

Based on above analysis, from the perspective of freight transport capacity operators, the main operating costs of HDTs during a full operation cycle include transportation equipment costs, operation and maintenance costs, environmental compensation costs for carbon and pollution reduction, and power battery recycling compensation costs. If recording the transportation equipment costs as $C_{\mathrm{TE}}$, the operating and maintenance costs as $C_{\mathrm{OM}}$, environmental compensation costs as $C_{\mathrm{EC}}$, and the battery recycling compensation costs as $C_{R C}$, an operating cost model for a single BS-HDT in a full operation cycle is established accordingly as Equation (1).

$$
C=C_{\mathrm{TE}}+C_{\mathrm{OM}}+C_{\mathrm{EC}}+C_{\mathrm{RC}}
$$

According to the "Compulsory Scrap Standard for Motor Vehicles" in China, HDTs, including semi-trailer tractors and full-trailer tractors, need to be scrapped when their travel mileage reaching $700,000 \mathrm{~km}$. Considering this requirement and the safe service life of electric HDT batteries at present, $500,000 \mathrm{~km}$ is selected as the target operating mileage for new BS-HDT in this paper. According to our survey, the daily operating mileage of the BS-HDT is $300 \mathrm{~km}$, and it works for 300 days per year on average. Based on this fact, the full operation cycle of BS-HDT can be estimated as about 5.5 years, and this number of the full operation cycle years can be used for subsequent analysis and sub-item cost calculation of HDT operation.

\subsubsection{Calculation of BS-HDT Sub-Items of Operating Cost}

The four sub-item operating costs are analyzed as follows:

- $\quad C_{\mathrm{TE}}$ (transportation equipment cost);

Because the freight transport capacity operator purchases BS-HDTs of total vehicles with power batteries and spare batteries for the battery-swapping stations while renting the stations' swapping service to customers in "Beijing Case", the $C_{\mathrm{TE}}$ of the freight transport capacity operator is mainly composed of BS-HDT purchase costs (after new energy vehicle purchase tax exempted), spare batteries purchase costs, and battery-swapping station rental costs. According to our survey, the battery-swapping station (S06-2400kW-8) leased by the freight transport capacity operator can serve 25 BS-HDTs per day, and each BS-HDT swaps batteries twice per day on average. According to the operator's data, the average annual purchase cost of spare batteries can be converted to USD 6957 and the rental cost of the battery-swapping station to about USD 13,333 for each BS-HDT.

- $\mathrm{C}_{\mathrm{OM}}$ (operating and maintenance cost);

The $C_{\text {OM }}$ mainly includes energy costs, labor costs, insurance costs, and maintenance costs. Among them, the average annual energy cost is calculated by multiplying the energy consumption per mileage of $0.20 \mathrm{USD} / \mathrm{km}$ by annual operating mileage. Converting power consumption of the battery-swapping station into the energy cost of a single BS-HDT, the average annual energy cost of a single BS-HDT is USD 9783. The labor cost is calculated as USD 28,986 per year regarding that a single HDT is generally equipped with two drivers. The average annual maintenance cost, including HDT repair and maintenance costs, is calculated at $0.4 \%$ of the corresponding equipment cost [9]. Because there is no insurance rate standard for BS-HDTs yet, the insurance premium of BS-HDTs is paid according to that of traditional D-HDTs. In order to reduce calculation complexity of HDT insurance that fluctuates year by year, the annual insurance cost of D-HDTs is assumed to remain 
unchanged, which is USD 649 per year [10]. Considering that the value of BS-HDT is about 1.75 times that of D-HDT, the annual insurance cost of BS-HDT is simply estimated to be USD 1136.

- $\quad C_{\mathrm{EC}}$ (environmental compensation cost);

The $C_{\mathrm{EC}}$ includes the compensation of the operation cost by relative reductions of carbon emissions and pollutant emissions. Driven by the "Double Carbon" goal, the environmental compensation cost $C_{\mathrm{EC}}$ can indirectly participate in the future carbon trading process. $C_{\mathrm{EC}}$ can be calculated by Equation (2).

$$
C_{\mathrm{EC}}=N\left(\alpha_{1} E_{\mathrm{CO} 2}+\alpha_{2} E_{\text {Pollutant }}\right)
$$

In Equation (2), $E_{\mathrm{CO} 2}$ is the average annual $\mathrm{CO}_{2}$ (including a small amount of carboncontaining emissions) emission reductions of a single BS-HDT. Referring to a previous study on the value of electric vehicles in reducing carbon emissions [11], carbon emission reduction compensation coefficient $\alpha_{1}$ is determined as $5.65 \mathrm{USD} /$ ton in this paper. $E_{\text {Pollutant }}$ is the annual average pollutant (including $\mathrm{HC}, \mathrm{NO}_{\mathrm{x}}, \mathrm{SO}_{2}, \mathrm{PM}_{\mathrm{x}}$, etc.) emission reductions of a single BS-HDT. Because current D-HDT needs to add urea to convert $\mathrm{NO}_{\mathrm{x}}$ into $\mathrm{N}_{2}$ and water to discharge and carbon-containing emissions have been involved in carbon compensation, $E_{\text {Pollutant }}$ mainly includes the emission reduction compensation of $\mathrm{SO}_{2}$ and $\mathrm{PM}_{\mathrm{x}}$. According to a previous study on the evaluation of the benchmark price of $\mathrm{SO}_{2}$ emission rights in a certain city, the emission reduction value of $\mathrm{SO}_{2}$ is $258.52 \mathrm{USD} /$ ton [12] Based on the average conversion of the comprehensively considered $\mathrm{HC}, \mathrm{NO}_{\mathrm{x}}$, and $\mathrm{PM}_{\mathrm{x}}$ contained in D-HDT emission [13,14], the pollutant emission reduction compensation coefficient $\alpha_{2}$ is determined as $217.39 \mathrm{USD} /$ ton. $N$ is the number of years of the full operation cycle life time of BS-HDT, and $N$ equals to 5.5, as analyzed in Section 3.2.1.

- $\quad C_{\mathrm{RC}}$ (battery recycling compensation cost);

Because the operating cost can be compensated by tapping the remaining value at the end of full operation cycle of BS-HDT after decommissioned batteries are recycled, the $C_{\mathrm{RC}}$ is usually calculated by Equation (3).

$$
C_{\mathrm{RC}}=-\beta M C_{\text {Battery }}
$$

In Equation (3), $\beta$ is the battery recycling coefficient and set to $30 \%$ according to the

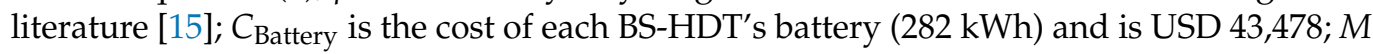
is the number of batteries converted to a single BS-HDT. Regarding the fact that a single battery-swapping station fully equipped with seven spare batteries can serve 25 BS-HDTs, $M$ can be converted to $1.28((7+25) \div 25=1.28)$.

\subsubsection{Calculation of BS-HDT Operating Cost}

By synthesizing the analysis in Section 3.2.2 and substituting the operating data obtained from our survey and literature research into Equation (1), the sub-items and total operating costs of BS-HDT for a full operation cycle are calculated, with results shown in Table 2.

\begin{tabular}{|c|c|c|c|}
\hline \multirow{2}{*}{\multicolumn{2}{|c|}{ Operating Costs of a Single BS-HDT }} & \multicolumn{2}{|c|}{ Amount (USD) } \\
\hline & & $\begin{array}{c}\text { Rental Cost of } \\
\text { Battery-Swapping } \\
\text { Station Considered }\end{array}$ & $\begin{array}{c}\text { Rental Cost of } \\
\text { Battery-Swapping } \\
\text { Station Unconsidered }\end{array}$ \\
\hline \multirow{3}{*}{$\begin{array}{c}C_{\mathrm{TE}} \text { (Transportation } \\
\text { Equipment Cost) }\end{array}$} & Vehicle purchase & 101,449 & 101,449 \\
\hline & $\begin{array}{c}\text { Annual rental of spare } \\
\text { batteries }\end{array}$ & 6957 & 6957 \\
\hline & $\begin{array}{c}\text { Annual rental of } \\
\text { battery-swapping station }\end{array}$ & 13,333 & 0 \\
\hline
\end{tabular}

Table 2. Calculation of a single BS-HDT operating costs in a full operation cycle (5.5 years). 
Table 2. Cont.

\begin{tabular}{|c|c|c|c|}
\hline \multirow{2}{*}{\multicolumn{2}{|c|}{ Operating Costs of a Single BS-HDT }} & \multicolumn{2}{|c|}{ Amount (USD) } \\
\hline & & $\begin{array}{c}\text { Rental Cost of } \\
\text { Battery-Swapping } \\
\text { Station Considered }\end{array}$ & $\begin{array}{c}\text { Rental Cost of } \\
\text { Battery-Swapping } \\
\text { Station Unconsidered }\end{array}$ \\
\hline \multicolumn{2}{|c|}{$C_{\mathrm{TE}}(5.5$ years $)$} & 213,043 & 139,710 \\
\hline \multirow{4}{*}{$\begin{array}{l}\text { COM }_{\mathrm{OM}}(\text { Operating and } \\
\text { Maintenance Cost) }\end{array}$} & Annual energy cost & 9783 & 9783 \\
\hline & Annual labor cost & 28,986 & 28,986 \\
\hline & Annual insurance cost & 1136 & 1136 \\
\hline & Annual maintenance cost & 435 & 435 \\
\hline \multicolumn{2}{|c|}{$C_{\mathrm{OM}}(5.5$ years $)$} & 221,865 & 221,865 \\
\hline \multirow{2}{*}{$\begin{array}{l}C_{E C} \text { (Environmental } \\
\text { Compensation Cost) }\end{array}$} & $\begin{array}{l}\text { Annual carbon emission } \\
\text { reductions compensation cost }\end{array}$ & -138 & -138 \\
\hline & $\begin{array}{l}\text { Annual pollutant emission } \\
\text { reduction compensation cost }\end{array}$ & -326 & -326 \\
\hline \multicolumn{2}{|c|}{$C_{\mathrm{EC}}(5.5$ years $)$} & -2555 & -2555 \\
\hline \multicolumn{2}{|c|}{$C_{\mathrm{RC}}$ (Battery Recycling Compensation Cost) } & $-16,696$ & $-16,696$ \\
\hline \multicolumn{2}{|c|}{$\begin{array}{c}\text { Total Operating Costs in a Full Operation Cycle } \\
\text { (5.5 years) }\end{array}$} & 415,658 & 342,325 \\
\hline
\end{tabular}

\subsection{Comparison of HDT Operating Economy under Four Energy Supplement Modes}

Based on the BS-HDT operating cost model in Section 3.2.1, taking the "Beijing Case" as prototype and $500,000 \mathrm{~km}$ as target operating mileage, we calculate the operating cost of a single HDT under the four different energy supplement modes (BS-HDT, C-HDT, D-HDT, and FC-HDT) from the perspective of a freight transport capacity operator. In addition, comparison and analysis of the operating costs are followed.

\subsubsection{Analysis of Sub-Items of HDT Operating Cost}

Deploying composition model of BS-HDT operating cost in Section 3.2.2, operating cost compositions of C-HDT, FC-HDT, and D-HDT will be respectively analyzed in this section:

- $\quad C_{\mathrm{TE}}$ (transportation equipment cost);

New energy vehicles, including C-HDT, FC-HDT, and BS-HDT, can be free from vehicle purchase tax, while those purchasing D-HDT need to pay a $10 \%$ vehicle purchase tax. Due to the low popularity of hydrogenation stations, it is assumed that the operation of FC-HDT also leases the hydrogenation station by using the financial lease of the batteryswapping station for reference. Because the energy supplement facilities of C-HDT and D-HDT have a high popularity already, the rental cost of charging and refuel facilities is not considered. Additionally, battery costs do not exist for C-HDTs, FC-HDTs, and D-HDTs in the transportation equipment cost.

- $\quad C_{\mathrm{OM}}$ (operating and maintenance cost);

In terms of operating and maintenance cost, given that D-HDT and FC-HDT have a similar energy supplement time length as that of BS-HDT, it can be simply set that the daily operating mileage of D-HDT and FC-HDT is about $300 \mathrm{~km}$, as is that of BS-HDT, and they also take 5.5 years to complete the target operating mileage of $500,000 \mathrm{~km}$. However, the charging time of C-HDT is about 90 minutes, which reduces its daily operating mileage to $200 \mathrm{~km}$, and it takes 8 years for C-HDT to complete the target operating mileage. The labor cost of C-HDT, FC-HDT, and D-HDT is assumed to be USD 28,986 per year, referring to that of BS-HDT, and the maintenance cost is $0.4 \%$ of their equipment cost, referring to the calculation method of BS-HDT. Meanwhile, the urea cost of D-HDT should also be considered in D-HDT operating costs. Because the urea consumption rate of D-HDT 
is $12.5 \mathrm{~g} / \mathrm{km}$ according to our survey and the cost of urea is $0.72 \mathrm{USD} / \mathrm{kg}$, the annual cost of urea for D-HDT is USD 815. The average annual insurance cost of D-HDT is USD 649 while insurance costs of C-HDT and FC-HDT are converted according to the ratio of vehicle value.

- $\quad C_{\mathrm{EC}}$ (environmental compensation cost);

A single D-HDT can emit 1.5 tons of atmospheric pollutants, including $\mathrm{HC}, \mathrm{NO}_{\mathrm{x}}, \mathrm{SO}_{2}$, and $\mathrm{PM}_{\mathrm{x}}$ per year [16]. According to the calculation of the carbon trading network, the $\mathrm{CO}_{2}$ emission amount of D-HDT over 3.5 tons is $271.6 \mathrm{~g} / \mathrm{km}$ [17], and the annual $\mathrm{CO}_{2}$ emission of a single D-HDT can hence be calculated to be 24.5 tons. Therefore, the annual $\mathrm{CO}_{2}$ emission reductions of BS-HDT and FC-HDT are both 16.3 tons. However, the daily operating mileage of C-HDT is $200 \mathrm{~km}$, which is two-thirds of the daily operating mileage of D-HDT. Thus, the annual $\mathrm{CO}_{2}$ emission reduction of C-HDT is two-thirds of the annual $\mathrm{CO}_{2}$ emission of D-HDT, which is 16.3 tons. Simply viewing the comparison results, the environmental protection compensation cost of D-HDT is zero while the environmental protection compensation costs of the three types of new energy trucks, BS-HDT, C-HDT, and FC-HDT, are all negative.

- $\quad C_{\mathrm{RC}}$ (battery recycling compensation cost);

Because only electric HDTs have battery recycling compensation for the operating cost, the battery recycling compensation cost of D-HDT and FC-HDT is zero while that of BS-HDT and C-HDT is negative. The battery recycling coefficient $\beta$ of BS-HDT can be set as $30 \%$ according to the literature and our survey. Given that BS-HDT's batteries usually adopt a concentrated and slow-charging mode at night and hence they are healthier than the batteries of C-HDT, the $\beta$ of C-HDT can be set as $25 \%$.

\subsubsection{Calculation of Operating Cost of HDT under Different Energy Supplement Modes}

Based on the operating cost model of a single BS-HDT in a full operation cycle and the analysis of operating cost of HDTs under three other energy supplement modes, data obtained from investigation and literature research are substituted into Equation (1), and the operating costs of a single HDT under the four different energy modes (BS-HDT, CHDT, D-HDT, and FC-HDT) are calculated and compared. Calculation results are shown in Table 3.

Table 3. Calculation results of operating costs of a single HDT under the four energy supplement modes.

\begin{tabular}{|c|c|c|c|c|c|}
\hline \multirow{2}{*}{\multicolumn{2}{|c|}{ Operating Costs of a Single HDT }} & \multicolumn{4}{|c|}{ Amount (USD) } \\
\hline & & BS-HDT & C-HDT & D-HDT & FC-HDT \\
\hline \multirow{4}{*}{$\begin{array}{l}C_{\mathrm{TE}}(\text { transportation } \\
\text { equipment cost) }\end{array}$} & Vehicle purchase & 101,449 & 101,449 & 57,971 & 130,435 \\
\hline & Vehicle purchase tax & 0 & 0 & 5797 & 0 \\
\hline & $\begin{array}{c}\text { Annual rental of spare } \\
\text { batteries }\end{array}$ & 6957 & 0 & 0 & 0 \\
\hline & $\begin{array}{l}\text { Annual rental of energy } \\
\text { supplement station * }\end{array}$ & 13,333 & 0 & 0 & 28,986 \\
\hline \multicolumn{2}{|c|}{$C_{\mathrm{TE}}$ (8 years for C-HDT, 5.5 years for others) } & $\begin{array}{c}213,043 \\
(139,710 *) \\
\end{array}$ & 101,449 & 63,768 & 289,855 \\
\hline \multirow{4}{*}{$\begin{array}{l}\mathrm{C}_{\mathrm{OM}} \text { (operating and } \\
\text { maintenance cost) }\end{array}$} & Annual energy cost & 9783 & 6522 & 31,826 & 73,043 \\
\hline & Annual labor cost & 28,986 & 28,986 & 28,986 & 28,986 \\
\hline & Annual insurance cost & 1136 & 1136 & 649 & 1461 \\
\hline & Annual maintenance cost & 435 & 406 & 696 & 870 \\
\hline
\end{tabular}


Table 3. Cont.

\begin{tabular}{|c|c|c|c|c|c|}
\hline \multirow{2}{*}{\multicolumn{2}{|c|}{ Operating Costs of a Single HDT }} & \multicolumn{4}{|c|}{ Amount (USD) } \\
\hline & & BS-HDT & C-HDT & D-HDT & FC-HDT \\
\hline \multicolumn{2}{|c|}{$C_{\mathrm{OM}}$ (8 years for C-HDT, 5.5 years for others) } & 221,865 & 296,394 & 341,861 & 573,977 \\
\hline \multirow{2}{*}{$\begin{array}{l}C_{\mathrm{EC}} \text { (environmental } \\
\text { compensation cost) }\end{array}$} & $\begin{array}{l}\text { Annual carbon emission } \\
\text { reductions } \\
\text { compensation cost }\end{array}$ & -138 & -92 & 0 & -138 \\
\hline & $\begin{array}{l}\text { Annual pollutant emission } \\
\text { reduction } \\
\text { compensation cost }\end{array}$ & -326 & -217 & 0 & -326 \\
\hline \multicolumn{2}{|c|}{$C_{\mathrm{EC}}$ (8 years for C-HDT, 5.5 years for others) } & -2555 & -2477 & 0 & -2555 \\
\hline \multicolumn{2}{|c|}{$C_{R C}$ (battery recycling compensation cost) } & $-16,696$ & $-10,870$ & 0 & 0 \\
\hline \multicolumn{2}{|c|}{ Total Operating Costs of a Single HDT } & $\begin{array}{c}415,658 \\
(342,325 *)\end{array}$ & 384,497 & 405,629 & 861,277 \\
\hline
\end{tabular}

* Amount in brackets does not consider the lease of battery-swapping station.

\section{Discussion}

First of all, we discuss the results of the sub-items' costs and total operating costs of BSHDT in Table 2. We can see that the operating and maintenance cost is the highest in a single BS-HDT operating cost during a full operation cycle, accounting for $53 \%$ of total operating costs and followed by the transportation equipment cost. There will be more room for reduction in transportation equipment cost in the future when rental of battery-swapping stations is negligible with their popularization. Battery recycling compensation cost is higher than the compensation cost of carbon emission reduction and pollutant emission reduction. With the implementation of "Double Carbon" strategy, the requirements for reducing carbon emissions in the transportation sector will be more stringent in the future; thus, the environmental compensation effect of the BS-HDT operating cost is expected to increase, which will help to reduce the BS-HDT operating cost and improve the operating economy of BS-HDT further.

Afterwards, we discuss the calculation results of operating costs of a single HDT under the four energy supplement modes shown in Table 3. This operating cost economy comparative analysis is based on the common condition of taking the "Beijing Case" as the prototype scenario and 500,000 $\mathrm{km}$ as the target operating mileage. Given that batteryswapping stations have not yet been popularized and the rental cost of battery-swapping stations is high and should be paid by freight transport capacity operators, C-HDT has the lowest total operating cost among the four types of HDTs in different energy supplement modes during a full operation cycle (5.5 years). Under such conditions, C-HDT's total operating cost is approximately USD 384,497 and about USD 20,290 lower than that of D-HDT. If the daily operating mileage of C-HDT can also reach $300 \mathrm{~km}$, its full operating cycle will be shortened to 5.5 years. According to our calculations, the total operating cost of C-HDT is USD 310,583. Among HDTs under the four energy supplement modes, C-HDT still has the lowest operating cost. FC-HDT has the highest total operating cost, which is about USD 861,277 and 2.1 times that of D-HDT. When battery-swapping stations are popularized and the rental of battery-swapping stations does not need to be considered only by freight transport capacity operators, the lowest total cost of HDT under the four energy supplement modes during a full operating cycle (5.5 years) is that of BS-HDT, which is about USD 342,325 and about USD 62,319 lower than that of D-HDT. In terms of battery recycling compensation cost, C-HDT's is higher than BS-HDT's, which indicates that the batteries operated in battery-swapping mode have a higher recycling value. In addition, battery-swapping mode is conducive to extending the service life of batteries and improving their health. 


\section{Conclusions}

This paper originally compares the operating costs of HDTs under the four different energy supplement modes currently in operation in China and points out the future development trend of HDT electrification. This paper also originally embodies the environmental protection value of HDT electrification in the operating cost model and quantifies the environmental protection contribution. As you can see from the results, BS-HDT has good cost economy in a full operation cycle under the specific scenario of medium and short-distance heavy-haul transportation in China. This economy will be further improved with the popularization of battery-swapping stations.

The operating cost model of BS-HDT during a full operation cycle in this paper can provide a theoretical reference for studying the operating cost economics of other electric commercial vehicle types. The comparative research method in this paper can also be applied to compare the operating cost of commercial vehicles under different energy supplement modes, such as an economic comparative study of taxis under the five energy supplement modes of gasoline refueling, charging, battery-swapping, hybrid, and hydrogen fuel cell modes. Moreover, the results of calculation and comparison of the operating economics of HDTs under the four different energy supplement modes in China can provide a practical reference for HDTs' research and development, production, vehicle type selection, and operation mode selection for relevant stakeholders, including HDT makers, freight transport capacity operators, investors, etc.

In terms of limitations, the survey data are practical but some defects may exist. Although most of the data can reflect the relative level among HDTs under different energy supplement modes, there may be some errors in the absolute quantity, which affects the calculation accuracy of the operating cost. Moreover, the calculation method of environmental compensation cost in this operating cost model may need to be further studied.

The Ministry of Industry and Information Technology of China and the National Energy Administration decided to jointly organize and launch the nationwide pilot application of the battery-swapping mode for new energy vehicles from the second half of 2021, which will be more conducive to facilitating the construction of battery-swapping stations and promote the innovation of "vehicle and battery separation" mode, hence improving the economy of BS-HDT. The promotion of the "Beijing Case" operation mode can be accelerated and expanded to more cities and applicable scenarios, such as short-transfer within a park and municipal sanitation, which can help speed up HDT electrification and make a greater contribution to energy conservation and emission reduction in China and even the world. To speed up the development of BS-HDTs, there needs to be improvement of the operation economy, allowing freight transport capacity operators as well as all stakeholders more power to develop sustainably. In order to reduce adversities hindering the BS-HDT operating economy and to support the construction of battery-swapping stations, it is crucial to remove obstacles of inconsistent battery standards and a lack of positive development modes for BS-HDT vehicle productions. For example, the manufacturers of electric HDT should try their best to adopt the forward-development mode instead of the former reverse-development mode so as to remove the existing inconsistent design of the battery package, which makes the operation of the battery-swapping mode difficult. Meanwhile, the absence of more detailed policy on the priority of right of way should be addressed by local governments. It is recommended that freight transport capacity operators, major HDT makers, battery-swapping technology providers, and other multi-party entities strengthen collaborative innovation while national government and local governments actively release policies, creating better conditions for more successful integration of BS-HDTs, autonomous driving, and smart transportation technology with ecology.

In the future, after BS-HDTs are further operated on a large scale, we can further study the impact of the cost reduction of the battery-swapping station on the BS-HDT operating costs, as well as the latest comparison of the operating cost of HDTs under four different energy supplement modes. We can also evaluate the operating economy of BS-HDT more comprehensively by surveying actual operating revenue in addition to only studying the 
costs. Moreover, we can follow the gradually increasing application of the "vehicle and battery separation" mode in HDTs' electrification and the changes it will make to the current traditional HDT operation mode. Under the "vehicle and battery separation" mode, the change of cost structure and economic of BS-HDTs will become one of our key research directions in the future. In addition, with the development of battery technology and the improvement of battery energy density, ways to adjust the economic indicators such as the increase of equipment cost, the changes of operation efficiency, and daily energy costs are also one of our future research directions.

Author Contributions: Conceptualization, X.W., P.L. and X.L.; methodology, X.W., P.L. and X.L.; software, P.L.; validation, X.W., P.L. and X.L.; formal analysis, X.W.; investigation, X.W., P.L. and X.L.; resources, X.W.; data curation, P.L.; writing—original draft preparation, P.L. and X.L.; writing—review and editing, X.W. and P.L.; visualization, P.L.; supervision, X.W.; project administration, X.W.; funding acquisition, X.W. All authors have read and agreed to the published version of the manuscript.

Funding: This research was funded by the National Social Science Foundation of China (Grant No. 19BJY073).

Data Availability Statement: Not applicable.

Acknowledgments: The authors thank the assistance from Dongjiang Zhang and Xikun Ding of Shanghai Enneagon Energy Technology Co., Ltd., and Shi Wu of School of Automotive Studies, Tongji University.

Conflicts of Interest: The authors declare no conflict of interest.

\section{References}

1. Jing, X.; Dongguang, C. Analysis on the characteristics of road freight transport in Heilongjiang province. Transpoworld 2020, $23,17-19$.

2. Bingxiang, S.; Tingting, H.; Junlong, N. Research on evaluation and prediction of operation cost of pure electric vehicle based on power exchange and battery lease mode. Electr. Technol. 2014, 29, 316-322.

3. Yunfei, W. The economic account of saving 75,000 CNY per year for Hualing Xingma battery-swapping heavy-duty truck. Commer. Veh. News 2020, 22-23.

4. Yixin, C.; Hewu, W.; Qiang, Y.; Minggao, O. The business model of charging or battery-swapping for electric taxis in Shenzhen and Hangzhou. J. Automot. Saf. Energy 2013, 4, 54-60.

5. China Committee of Electric Vehicles 100 Members. The Electrification of Heavy-Duty Truck Is Imperative. Available online: https:/ / chuneng.bjx.com.cn/news/20200729/1092746.shtml (accessed on 15 April 2021).

6. Xueqi, H.; Bo, H.; Xinmei, Y. Full life cycle economic analysis of China's ultra-fast charging stations. Power Constr. 2018, 39, 15-20.

7. Wen, H.; Xuhong, L.; Jie, H. Research on operation cost of highway freight vehicles based on axle type classification. Highw. Transp. Technol. 2005, 9, 170-174.

8. Qingyin, D.; Quanyin, T.; Shuoshuo, H.; Jinhui, L. Recovery mode and economic analysis of power batteries for new energy vehicles in Beijing. Sci. Technol. Manag. Res. 2020, 40, 219-225.

9. Serradilla, J.; Wardle, J.; Blythe, P.; Gibbon, J. An evidence-based approach for investment in rapid-charging infrastructure. Energy Policy. 2017, 106, 514-524. [CrossRef]

10. Truck Insurance. Available online: https:/ / zhidao.baidu.com/question/630783911676913924.html (accessed on 26 April 2021).

11. Yu, S.; Hua, Z.; Zhihan, Y. Energy saving and emission reduction benefit analysis and environmental impact assessment of electric vehicles throughout the life cycle. Resour. Ind. 2021, 23, 100-109. [CrossRef]

12. Guoqian, S. Research on Carbon Asset Value Evaluation. Master's Thesis, Yunnan University of Finance and Economics, Kunming, China, 2016.

13. Chenjing, L.; Hongqing, S.; Mingxu, Y. The development trend and carbon emission and PM2.5 emission characteristics of different types of heavy trucks in the Beijing-Tianjin-Hebei region. Environ. Eng. 2017, 2, 427-432.

14. Jiapeng, Y. Analysis of the operating cost of air pollution control facilities. Heilongjiang Sci. Technol. Inf. $2009,28,217$.

15. Hualing, L.; Yongzhen, C.; Wenji, S. Recycling mode and economic analysis of electrode materials for lithium-ion power batteries. New Energy Progress 2018, 6, 505-511.

16. CIMC. Reduced 3,000 Tons of Air Pollutants per Year. Available online: http://www.ecv360.com/heavytruck/201906/47044.html (accessed on 6 May 2021).

17. Carbon Emissions Trading Website. Carbon Emissions of Trucks. Available online: http://www.tanpaifang.com/tanjiliang/2019 /0831/65464.html (accessed on 9 May 2021). 